\title{
Current Trends and Results of Endovascular Treatment of Unruptured Intracranial Aneurysms at a Single Institution in the Flow-Diverter Era
}

\author{
(D) Petr, DW. Brinjikji, DH. Cloft, DD.F. Kallmes, and (D) Lanzino
}

\begin{abstract}
BACKGROUND AND PURPOSE: During the past several years, the number of unruptured aneurysms treated with endovascular techniques has increased. Traditionally, coil embolization was the treatment of choice for these lesions; however, recently flow diversion has become a viable, and in some cases superior, treatment option. The current single-center study presents results and trends of endovascular treatment with flow diversion and coil embolization in an unselected group of patients with unruptured intracranial aneurysms in a "real world" setting during the flow-diverter era.
\end{abstract}

MATERIALS AND METHODS: Three hundred ten patients with 318 treated unruptured aneurysms from June 2009 to May 2015 were included. Patient demographics, clinical characteristics, aneurysm/treatment characteristics, and outcomes were collected prospectively. We studied the following: intensive care unit admission/reasons, perioperative and mid-/long-term complications, target aneurysm rupture, retreatment/recurrence rates, and long-term neurologic outcome using the mRS.

RESULTS: The flow-diverter group had a larger mean aneurysm size (12.3 $\pm 8.6 \mathrm{~mm}$ versus $8.7 \pm 6.3 \mathrm{~mm}, P<.0001)$. There were no significant differences in the immediate $(P=.43)$ and mid-/long-term complication rates $(P=.54)$ between groups. Periprocedural neurologic morbidity and mortality rates were $2.1 \%$ and $0.5 \%$ in the coiling group and $2.5 \%$ and $1.6 \%$ in the flow-diverter group. Patients with coiling were more likely to be retreated than those with flow diversion (14.8\% versus $5.7 \%, P=.009)$. Worsening of the mRS due to the target aneurysm was noted in only $3.2 \%$ of patients.

CONCLUSIONS: The endovascular treatment of unruptured aneurysms can be performed with very low rates of neurologic complications. Both flow-diverter and coil therapy were safe and effective.

ABBREVIATIONS: $\mathrm{FD}=$ flow diverter; $\mathrm{ICU}=$ intensive care unit; $\mathrm{PED}=$ Pipeline Embolization Device

D

uring the past several years, the number of unruptured aneurysms treated with endovascular techniques has increased. Traditionally coil embolization was the treatment of choice for these lesions; however, the introduction of endoluminal flow diversion has heralded the beginning of a new endovascular era. Flow diversion achieves high rates of aneurysm occlusion with acceptable safety profiles. ${ }^{1-6}$ However, with increasing experience and widespread use of flow diversion, several problems and complications have been recognized. ${ }^{7,8}$ These include intraparenchymal hemorrhage, postprocedural subarachnoid hemorrhage, and ischemic stroke. ${ }^{9,10}$

\footnotetext{
Received August 25, 2015; accepted after revision November 18.
}

From the Departments of Neurologic Surgery (O.P., G.L.) and Radiology (W.B., H.C., D.F.K., G.L.), Mayo Clinic, Rochester, Minnesota; and Department of Neurosurgery, (O.P.), Medical University, Innsbruck, Austria.

Please address correspondence to Giuseppe Lanzino, MD, Mayo Clinic, 200 1st St SW, Rochester, MN 55905; e-mail: lanzino.giuseppe@mayo.edu; @WBrinjikji

$\therefore$ Indicates article with supplemental on-line photos.

http://dx.doi.org/10.3174/ajnr.A4699
Newer endovascular treatment options allow better patient selection for flow-diversion and coiling techniques. At this stage, the potential influence of flow diversion on the use of coils in treatment of intracranial aneurysms remains unknown. ${ }^{11}$ These devices are being used in greater numbers of patients with various aneurysm locations and morphologies. ${ }^{6,12-14}$ While observing the changing endovascular treatment trends is interesting, it is crucial to assess the risk-benefit ratio for treatment by flow diverters (FDs) compared with coiling. The current single-center study presents results and trends of endovascular treatment with flow diversion and coil embolization in a group of unselected patients with unruptured intracranial aneurysms in a "real world" setting.

\section{MATERIALS AND METHODS}

\section{Patient Population and Data Collection}

Following institutional review board approval, all patients included in a prospective database of unruptured aneurysms from June 2009 to May 2015 were included in this study. Information collected in this database included patient demographics and 
baseline clinical characteristics, aneurysm characteristics, treatment characteristics, and treatment outcomes. Patient demographic data collected included age, sex, baseline symptoms, baseline neurologic status, history of subarachnoid hemorrhage, and family history of intracranial aneurysms. Aneurysm characteristics included location and size. Treatment characteristics included type of device used, number of flow diverters used, and use of stent or balloon assistance.

The periprocedural pharmacologic protocol for patients undergoing flow-diverter therapy was uniform throughout the study period. Starting clopidogrel (Plavix), $75 \mathrm{mg}$, and aspirin, $325 \mathrm{mg}$, daily for 5 days before the procedure was recommended. Postoperatively, patients were maintained on the same clopidogrel and aspirin dosage for 3 months. After 3 months, clopidogrel was discontinued for patients undergoing on-label treatment (ie, aneurysms of the internal carotid artery proximal to the takeoff of the posterior communicating artery). For cases that were not offlabel, and especially in high-risk locations, we have continued antiplatelet therapy for a longer time due to a potentially higher risk of thromboembolic events. Patients with aneurysms distal to the origin of the posterior communicating artery or involving the posterior circulation were usually maintained on clopidogrel for a longer time, and the antiplatelet therapy was recommended according to the results of their follow-up conventional angiography. After discontinuation of clopidogrel, low-dose aspirin (81 $\mathrm{mg}$ /day) indefinitely was recommended. Loading doses of clopidogrel and aspirin were given on the day before or the day of the procedure for patients who were not electively admitted. Platelet reactivity was not tested in any patient.

\section{Outcomes}

Treatment outcomes included intraprocedural and periprocedural technical events, clinical events (including aneurysm perforation, thrombosis, neurologic symptoms, medical symptoms, ophthalmologic symptoms, and groin complications), and late technical and clinical events at follow-up. Periprocedural complications were defined as those occurring within 30 days following the procedure, and late events were defined as events occurring after 30 days. Clinical follow-up was collected by telephone within the first 30 days, at the time of radiographic follow-up at 6 and 12 months and 3 years, and by telephone at 24 months. Clinical follow-up was obtained by a specialized nurse not directly involved with the original procedure. At the time of follow-up, patients were asked to rate themselves on the basis of the modified Rankin Scale. Patients were also asked to specify the reason for any score higher than zero. A baseline assessment, following the same methodology, was also obtained at the first encounter before aneurysm treatment.

For patients with flow diverters, radiologic follow-up with conventional angiography was recommended at 6, 12, and 36 months, and for patients with coiling, conventional angiography or MRA was recommended 6 or 12 months after the original procedure, depending on aneurysm characteristics. Afterward, imaging follow-up for patients with coiling was individualized according to various patient and aneurysm factors. Aneurysm occlusion on follow-up angiography, MRA, and/or CTA was categorized as "complete" (no filling of the aneurysm sac), "near- complete" (>90\% occlusion), and "incomplete" (<90\% occlusion). We also reported FD angiographic outcomes by the number of FDs used in treatment.

We studied the following outcomes: 1) the presence of perioperative complications, 2) mid- and long-term complications, 3) target aneurysm rupture, 4) retreatment rates, 5) major recurrence rates, and 6) long-term neurologic outcome. Long-term neurologic outcome was assessed by using the modified Rankin Scale and with the methodology detailed above. We also determined whether neurologic disability was secondary to the aneurysm or other symptoms (ie, back pain, intercurrent nonrelated illness, and so forth). "Neurologic morbidity" was defined as any neurologic deficit that appeared either due to target aneurysms or their endovascular treatment. "Neurologic mortality" was defined as any death of the patient related to target aneurysms and/or their treatment complications.

\section{Statistical Analysis}

Baseline characteristics and outcomes were compared between the flow-diverter and coiling groups. Descriptive statistics are presented as means and proportions. Means are presented with SDs. Categoric variables were compared by using a $\chi^{2}$ test, and continuous variables were compared by using a Student $t$ test. Statistical significance was a $P$ value $<.05$. All statistical analysis was performed by using JMP 10.0 (SAS Institute, Cary, North Carolina).

\section{RESULTS}

\section{Patient Population}

During the study period (September 2009 to April 2015), 332 patients were recommended for endovascular treatment of 341 unruptured intracranial aneurysms. Twenty-two patients with 23 target aneurysms were excluded due to missing Minnesota Research Authorization. Three hundred ten patients with 318 target aneurysms treated with endovascular coiling or flow diverters were included in the study. One hundred ninety-six aneurysms were initially treated with coiling, and 87 aneurysms were initially treated with flow diversion. Thirty-five aneurysms were treated with flow diversion following recanalization after coiling (these aneurysms were either coiled at other institutions or coiled at our institution prior to the study period). Of the 318 target aneurysms treated during the study period, 34 required retreatment. Thus, there were 352 aneurysm treatments during the study period. Demographic and aneurysm characteristics are listed in Table 1 . Two hundred forty-nine patients $(80.3 \%)$ were women, and 61 patients $(19.7 \%)$ were men. The mean age at presentation was 57.4 years (range, 20-83 years). Most of the treated aneurysms were asymptomatic (249 aneurysms, 78.3\%), while 69 aneurysms $(21.7 \%)$ were symptomatic. Headache $(11.0 \%)$ and visual problems $(5.7 \%)$ were the most common presenting symptoms. Two hundred ten aneurysms (66.0\%) were incidentally discovered.

Radiologic follow-up was available for 290 aneurysms (91.2\%), while 28 aneurysms (8.8\%) have not yet undergone radiologic follow-up because they were recently treated. The mean length of radiologic follow-up was 20 months (range, 0-67 months), and the mean clinical follow-up was 23.4 months (range, 1-67 months). From 2009 to 2014, the proportion of aneurysms treated with flow diversion increased from $15.8 \%$ to 


\begin{tabular}{|c|c|c|c|c|}
\hline & $\begin{array}{l}\text { All Patients } \\
\qquad(n=310)\end{array}$ & $\begin{array}{l}\text { Patients with Coiling } \\
\qquad(n=188)\end{array}$ & $\begin{array}{l}\text { Patients with Flow Diverters } \\
\qquad(n=122)\end{array}$ & $P$ Value \\
\hline Mean age (SD) (yr) & $57.4(20-83)$ & $57.9(24-80)$ & $55.7(23-80)$ & .10 \\
\hline Female sex (No.) (\%) & $249(80.3 \%)$ & $145(77.1 \%)$ & $104(85.2 \%)$ & .01 \\
\hline Mean (range) follow-up (mo) & $23.4(1-67)$ & $24.5(1-67)$ & $22.4(1-61)$ & \\
\hline No. of aneurysms & 318 & 196 & 122 & \\
\hline Aneurysm location & & & & $<.0001$ \\
\hline Cavernous ICA & $27(8.5 \%)$ & $1(0.5 \%)$ & $26(21.3 \%)$ & \\
\hline Paraclinoid/supraclinoid ICA & $104(32.7 \%)$ & $34(17.3 \%)$ & $70(57.4 \%)$ & \\
\hline ICA terminus & $13(4.1 \%)$ & $10(5.1 \%)$ & $3(2.5 \%)$ & \\
\hline ICA PcomA & $36(11.3 \%)$ & $24(12.2 \%)$ & $12(9.8 \%)$ & \\
\hline MCA & $19(6.0 \%)$ & $16(8.2 \%)$ & $3(2.5 \%)$ & \\
\hline ACA/AcomA & $56(17.6 \%)$ & $56(28.6 \%)$ & $0(0 \%)$ & \\
\hline Vertebral artery & $2(0.6 \%)$ & $1(0.5 \%)$ & $1(0.8 \%)$ & \\
\hline Basilar artery & $37(11.6 \%)$ & 35 (17.9\%) & $2(1.6 \%)$ & \\
\hline PICA & $10(3.21)$ & $7(3.6 \%)$ & $3(2.5 \%)$ & \\
\hline Other & $14(4.4 \%)$ & $12(6.1 \%)$ & $2(1.6 \%)$ & \\
\hline Anterior circulation & $263(82.7 \%)$ & $148(75.5 \%)$ & $115(94.3 \%)$ & \\
\hline Posterior circulation & $55(17.3 \%)$ & $48(24.5 \%)$ & $7(5.7 \%)$ & \\
\hline Mean size $(\mathrm{SD})$ & & $8.7( \pm 6.3 \mathrm{~mm})$ & $12.3( \pm 8.6 \mathrm{~mm})$ & $<.0001$ \\
\hline Small $(<5 \mathrm{~mm})$ & $60(18.9 \%)$ & $46(23.5 \%)$ & $14(11.5 \%)$ & \\
\hline Medium (5-15 mm) & $207(65.1 \%)$ & $131(66.8 \%)$ & $76(62.3 \%)$ & \\
\hline Large (16-25 mm) & $26(8.2 \%)$ & $11(5.6 \%)$ & $15(12.3 \%)$ & $<.0001$ \\
\hline Giant (>25 mm) & $25(7.9 \%)$ & $8(4.1 \%)$ & $17(13.9 \%)$ & $<.0001$ \\
\hline \multicolumn{5}{|l|}{ Symptoms } \\
\hline Asymptomatic & $249(78.3 \%)$ & $159(81.1 \%)$ & $90(73.8 \%)$ & \\
\hline Symptomatic & $69(21.7 \%)$ & $37(18.9 \%)$ & $32(26.2 \%)$ & \\
\hline Headaches & $35(11.0 \%)$ & $21(10.7 \%)$ & 14 (11.5\%) & \\
\hline Visual problems & $18(5.7 \%)$ & $9(4.6 \%)$ & $9(7.4 \%)$ & \\
\hline Aneurysm discovered incidentally & $210(66.0 \%)$ & $144(73.5 \%)$ & $66(54.1 \%)$ & \\
\hline
\end{tabular}

Note:-PcomA indicates posterior communicating artery; AcomA, anterior communicating artery; ACA, anterior cerebral artery; PICA, posterior inferior cerebellar artery.

$48.8 \%$ (On-line Fig 1). Accordingly, in the proximal (to the origin of the posterior communicating artery) ICA aneurysm group, the proportion of aneurysms treated with flow diverters increased from $27.3 \%$ to $88.9 \%$ (On-line Fig 2).

Basic demographic characteristics between the 2 groups are summarized in Table 1. The flow-diverter group had a higher mean aneurysm size $(12.3 \pm 8.6 \mathrm{~mm}$ versus $8.7 \pm 6.3 \mathrm{~mm}, P<$ $.0001)$. There were more large and giant aneurysms in the FD group compared with the coiling group $(26.2 \%$ versus $9.7 \%, P<$ $.0001)$. There was a significant difference in the location of treated aneurysms between the 2 groups $(P<.0001)$ : Twenty-six cavernous sinus aneurysms $(21.3 \%)$ were treated with FDs compared with $1(0.5 \%)$ in the coil embolization group; 70 (57.4\%) supraclinoid/paraclinoid aneurysms were treated in the FD group versus $34(17.3 \%)$ aneurysms in the coiling group. All anterior cerebral artery/anterior communicating artery aneurysms (56/17.6\%) were treated with coiling only. Characteristics of treated aneurysms are summarized in Table 1.

\section{Angiographic Results}

Angiographic results and basic characteristics of techniques and devices are listed in Table 2. Radiologic follow-up was available for $290(91.2 \%)$ aneurysms, after a mean time of 20 months (range, 0-67 months), while 28 aneurysms (8.8\%) have not yet undergone radiologic follow-up.

Complete occlusion at the last radiologic follow-up was achieved in 165 (51.9\%) aneurysms, and near-complete occlusion, in 112 (35.2\%) aneurysms. Among patients with at least 6 months of imaging follow-up, the complete occlusion rate was
$55.1 \%(147 / 267)$ and the near-complete occlusion rate was $34.5 \%$ $(92 / 267)$. For patients with flow diverters with 6 months of imaging follow-up, the complete occlusion rate was $64.4 \%(67 / 104)$ and the near-complete occlusion rate was $22.1 \%$ (23/104). For patients with coiling with at least 6 months of imaging follow-up, the complete occlusion rate was $49.1 \%(80 / 163)$ and the nearcomplete occlusion rate was $42.3 \%$ (69/163).

Of 352 endovascular treatments and 318 treated unruptured aneurysms, major recurrences were present and retreated in 29 aneurysms $(14.8 \%)$ in the coiling group. In the FD group, there were no instances of recanalization; however, 7 aneurysms (5.7\%) were retreated due to persistent filling of the aneurysm sac. The rate of retreatment was significantly higher in the coiling group $(P=.009)$. Of 29 aneurysm retreatments in the coiling group, 18 $(9.2 \%)$ were retreated with recoiling; 2 (1.0\%), with surgical clipping; and 8 (4.1\%), with FDs. All 7 retreatments (5.7\%) from the FD group were retreated with the Pipeline Embolization Device (PED; Covidien, Irvine, California).

In the FD group, the overall rate of complete occlusion at last follow-up was $56.6 \%(69 / 122)$ and the near-complete occlusion rate was $21.3 \%(26 / 122)$. Complete occlusion rates were $49.5 \%$ (45/91) for patients treated with $1 \mathrm{FD}, 66.7 \%$ (12/18) for patients treated with 2 FDs, and $92.3 \%$ (12/13) for patients treated with $\geq 3$ FDs. These data are summarized in Table 3 .

\section{Technical Outcomes and Immediate Complications}

Immediate complications following the endovascular procedure occurred in 32 patients (10.3\%). These complications included 20 patients $(10.6 \%)$ from the coiling group and 12 patients $(9.8 \%)$ 


\begin{tabular}{|c|c|c|c|c|}
\hline & $\begin{array}{l}\text { All Patients/ } \\
\text { Treatments }(N=310 / 352)\end{array}$ & $\begin{array}{l}\text { Patients with Coiling/ } \\
\text { Treatments }(n=188 / 223)\end{array}$ & $\begin{array}{l}\text { Patients with Flow } \\
\text { Diverters/Treatments } \\
\text { ( } n=122 / 129)\end{array}$ & $P$ Value \\
\hline \multicolumn{5}{|l|}{ Coiling-assist devices } \\
\hline Balloon & $9 / 352(2.6 \%)$ & $9 / 223(4.0 \%)$ & NA & - \\
\hline Stent & $10 / 352(2.8 \%)$ & $10 / 223(4.5 \%)$ & NA & \\
\hline \multicolumn{5}{|l|}{ Flow diverter used } \\
\hline Pipeline & $124 / 352(35.2 \%)$ & NA & $124 / 129(96.1 \%)$ & - \\
\hline Surpass ${ }^{\mathrm{b}}$ & $5 / 352(1.4 \%)$ & NA & $5 / 129(3.9 \%)$ & \\
\hline \multicolumn{5}{|l|}{ Angiographic occlusion at last follow-up } \\
\hline Complete & $165 / 318(51.9 \%)$ & $96 / 196(49.0 \%)$ & $69 / 122(56.6 \%)$ & $<.0001$ \\
\hline Near-complete & $112 / 318(35.2 \%)$ & $86 / 196(43.9 \%)$ & $26 / 122(21.3 \%)$ & \\
\hline Incomplete & $41 / 318(12.9 \%)$ & $14 / 196(7.1 \%)$ & $27 / 122(22.1 \%)$ & \\
\hline $\begin{array}{l}\text { Angiographic follow-up for patients with } \\
\text { imaging } \geq 6 \text { mo posttreatment }\end{array}$ & & & & $<.0001$ \\
\hline Complete & $147 / 267(55.1 \%)$ & $80 / 163(49.1 \%)$ & $67 / 104(64.4 \%)$ & \\
\hline Near-complete & $92 / 267(34.5 \%)$ & $69 / 163(42.3 \%)$ & $23 / 104(22.1 \%)$ & \\
\hline Incomplete & $28 / 267(10.5 \%)$ & $14 / 163(8.6 \%)$ & $14 / 104$ (13.5\%) & \\
\hline Mean radiologic follow-up time (mo) & $20(0-67)$ & $20(0-67)$ & $20(0-61)$ & .46 \\
\hline Retreatment & & & & .009 \\
\hline Recoiling & $18 / 318(5.7 \%)$ & $18 / 196(9.2 \%)$ & $0 / 122(0.0 \%)$ & \\
\hline Retreatment with FD & $15 / 318(4.7 \%)$ & $8 / 196(4.1 \%)$ & $7 / 122(5.7 \%)$ & \\
\hline Clipping & $2 / 318(0.6 \%)$ & 2/186 (1.0\%) & $0 / 122(0.0 \%)$ & \\
\hline Recurrence & $36 / 318$ (11.3\%) & $29 / 196(14.8 \%)$ & $7 / 122(5.7 \%)$ & .009 \\
\hline
\end{tabular}

Note:-NA indicates not available.

a Three hundred ten patients received 352 treatments; 188 patients with coiling received 223 treatments, and 122 patients with flow diverters received 129 treatments.

${ }^{\mathrm{b}}$ Stryker Neurovascular, Kalamazoo, Michigan.

Table 3: Outcomes by number of flow diverters

\begin{tabular}{|c|c|c|c|c|}
\hline $\begin{array}{l}\text { Angiographic Occlusion } \\
\text { at Last Follow-Up }\end{array}$ & $\begin{array}{c}1 \\
\text { Device }\end{array}$ & $\begin{array}{c}2 \\
\text { Devices }\end{array}$ & $\begin{array}{c}\geq 3 \\
\text { Devices }\end{array}$ & $\begin{array}{c}122 \\
\text { Aneurysms }\end{array}$ \\
\hline Complete & $45(49.5 \%)$ & $12(66.7 \%)$ & $12(92.3 \%)$ & $69(56.6 \%)$ \\
\hline Near-complete & $22(24.1 \%)$ & $4(22.2 \%)$ & $0(0 \%)$ & $26(21.3 \%)$ \\
\hline Incomplete & $24(26.4 \%)$ & $2(11.1 \%)$ & $1(7.7 \%)$ & $27(22.1 \%)$ \\
\hline
\end{tabular}

from the FD group and are summarized in Table 4. Seven patients experienced TIAs $(2.3 \%)$, and 1 patient noted a deterioration of ophthalmoplegia $(0.3 \%)$. There was no significant difference in the immediate complication rate between both groups $(P=.43)$. Neurologic mortality rates were $0.5 \%$ in the coiling group and $1.6 \%$ in the FD group $(P=.70)$. Neurologic morbidity rates were $2.1 \%$ in the coiling group and $2.5 \%$ in the FD group $(P=.85)$.

The mean length of the hospital stay was not significantly different between the 2 groups ( 1.2 days for the coiling group and 1.3 days for the FD group, $P=.54$ ). There was a decreasing trend in the proportion of patients with flow diverters going to the intensive care unit (ICU) between 2009 and 2014 (100\% to 15.8\%). The same was true for patients with coiling (50\% to 16.7\%) (On-line Fig 3).

\section{Midterm and Long-Term Clinical Outcomes}

Midterm and long-term complications following endovascular procedures occurred in 12 patients (3.9\%) and are listed in Table 4. Midterm/long-term complications occurred in 6 patients (3.2\%) from the coiling group and 6 patients $(4.9 \%)$ from the FD group $(P=.54)$. Six patients $(1.9 \%)$ had thromboembolic complications, and 4 patients $(1.3 \%)$ experienced periorbital pain. Only 1 of all mid-/long-term complications (0.3\%) resulted in a permanent neurologic deficit. This 73-year-old woman with a left-sided giant symptomatic carotid cavernous aneurysm treated with flow diversion developed a permanent mild right-sided hemiparesis.
Clinical follow-up with mRS assessment before and after treatment was available for all patients, with a mean follow-up time of 23.4 months (range, 1-67 months). The mean length of clinical follow-up was not significantly different between groups (24.5 months; range, 1-67 months in the coiling group; and 22.4 months; range, 1-61 months in the FD group).

Ten patients (3.2\%) reported $\mathrm{mRS}$ worsening due to the target aneurysm or endovascular therapy ( 7 in the coiling group and 3 in the FD group). Three patients experienced postoperative rupture (1.0\%). Twenty-two patients $(7.1 \%)$ died during the study period; however, only $3(1.0 \%)$ of the deaths were related to their target aneurysms or stroke. One patient died following delayed rupture of a previously coiled unruptured aneurysm, 1 patient died from a distal intraparenchymal hemorrhage 8 days after treatment with a PED, and 1 patient had a posttreatment rupture from a giant left ICA aneurysm 11 months after PED deployment. Long-term neurologic outcomes are listed in Table 5. A summary of patients who experienced postoperative rupture is provided in Table 6.

\section{DISCUSSION}

Our consecutive prospective series of 318 aneurysms in 310 unselected patients demonstrated that endovascular treatment of unruptured aneurysms can be performed with low rates of neurologic complications and high rates of satisfactory angiographic occlusion. Both flow-diverter and coil therapy were safe and effective. However, coil treatment was associated with higher rates of recurrence and retreatment. Only $3.2 \%$ of patients noticed a deterioration of symptoms due to aneurysm or endovascular treatment. Our study also demonstrated that since the introduction of flow diversion at our institution, there has been a significant upward trend in the use of FDs as approximately 50\% of unruptured aneurysms are now treated by using these methods. 


\begin{tabular}{|c|c|c|c|c|c|c|c|}
\hline & $\begin{array}{c}\text { All } \\
\text { Patients } \\
(N=310)\end{array}$ & $\begin{array}{c}\text { All } \\
\text { Treatments } \\
(n=352)\end{array}$ & $\begin{array}{c}\text { Patients with } \\
\text { Coiling } \\
(n=188)\end{array}$ & $\begin{array}{l}\text { Coiling } \\
\text { Treatments } \\
(n=223)\end{array}$ & $\begin{array}{l}\text { Patients with Flow } \\
\text { Diverters }(n=122)\end{array}$ & $\begin{array}{c}\text { Flow-Diverter } \\
\text { Treatments } \\
(n=129)\end{array}$ & $\begin{array}{c}P \\
\text { Value }\end{array}$ \\
\hline \multicolumn{8}{|l|}{ ICU admission } \\
\hline Yes & $82(26.5 \%)$ & $93(26.4 \%)$ & $37(19.7 \%)$ & $45(20.2 \%)$ & 45 (36.9\%) & $48(37.2 \%)$ & .005 \\
\hline No & $228(73.5 \%)$ & $259(73.6 \%)$ & $151(80.3 \%)$ & $178(79.8 \%)$ & $77(63.1 \%)$ & $81(62.8 \%)$ & \\
\hline \multicolumn{8}{|l|}{ Reason for ICU admission } \\
\hline 1) Complexity & $39(12.6 \%)$ & 45 (12.8\%) & $16(8.5)$ & $20(9.0)$ & $23(18.9 \%)$ & 25 (19.4\%) & \\
\hline 2) Neurologic deterioration & $4(1.3 \%)$ & $4(1.1 \%)$ & $3(1.6 \%)$ & $3(1.3 \%)$ & $1(0.8 \%)$ & $1(0.8 \%)$ & \\
\hline 3) Intraoperative rupture & $3(1.0 \%)$ & $3(0.9 \%)$ & $3(1.6 \%)$ & $3(1.3 \%)$ & $0(0 \%)$ & $0(0 \%)$ & \\
\hline 4) Vessel occlusion & $6(1.9 \%)$ & $6(1.7 \%)$ & $1(0.5 \%)$ & $1(0.4 \%)$ & $5(4.1 \%)$ & $5(3.9 \%)$ & \\
\hline 5) Coil dislocation & $1(0.3 \%)$ & $1(0.3 \%)$ & $1(0.5 \%)$ & $1(0.4 \%)$ & NA & NA & \\
\hline 6) Pipeline & $14(4.5 \%)$ & $15(4.3 \%)$ & NA & NA & $14(11.5 \%)$ & $15(11.6 \%)$ & \\
\hline Immediate complications ( $<30$ days) & $32(10.3 \%)$ & $32(9.1 \%)$ & 20 (10.6\%) & $20(9.0 \%)$ & $12(9.8 \%)$ & $12(9.3 \%)$ & .43 \\
\hline Intraoperative rupture & $3(1.0 \%)$ & $3(0.9 \%)$ & $3(1.6 \%)$ & $3(1.3 \%)$ & $0(0 \%)$ & $0(0 \%)$ & \\
\hline Thromboembolic & $5(1.6 \%)$ & $5(1.4 \%)$ & $4(2.1 \%)$ & $4(1.8 \%)$ & $1(0.8 \%)$ & $1(0.8 \%)$ & \\
\hline TIA & $7(2.3 \%)$ & $7(2.0 \%)$ & $5(2.7 \%)$ & $5(2.2 \%)$ & $2(1.6 \%)$ & $2(1.6 \%)$ & \\
\hline Thrombus formation & $7(2.3 \%)$ & $7(2.0 \%)$ & $3(1.6 \%)$ & $3(1.3 \%)$ & $4(3.3 \%)$ & $4(3.1 \%)$ & \\
\hline Groin hematoma & $5(1.6 \%)$ & $5(1.4 \%)$ & $3(1.6 \%)$ & $3(1.3 \%)$ & $2(1.6 \%)$ & $2(1.6 \%)$ & \\
\hline Intraoperative aneurysm perforation & $3(1.0 \%)$ & $3(0.9 \%)$ & $3(1.6 \%)$ & $3(1.3 \%)$ & $0(0 \%)$ & $0(0 \%)$ & \\
\hline Complication-related morbidity & $4(1.3 \%)$ & $4(1.1 \%)$ & $2(1.1 \%)$ & $2(0.9 \%)$ & $2(1.6 \%)$ & $2(1.6 \%)$ & \\
\hline Complication-related mortality & $3(1.0 \%)$ & $3(0.9 \%)$ & $1(0.5 \%)$ & $1(0.4 \%)$ & $2(1.6 \%)$ & $2(1.6 \%)$ & \\
\hline Mid- and long-term complications & $12(3.9 \%)$ & $12(3.4 \%)$ & $6(3.2 \%)$ & $6(2.7 \%)$ & $6(4.9 \%)$ & $6(4.7 \%)$ & .54 \\
\hline Thromboembolic, stroke & $6(1.9 \%)$ & $6(1.7 \%)$ & $4(2.1 \%)$ & $4(1.8 \%)$ & $2(1.6 \%)$ & $2(1.6 \%)$ & \\
\hline Periorbital pain & $4(1.3 \%)$ & $4(1.1 \%)$ & $2(1.1 \%)$ & $2(0.9 \%)$ & $2(1.6 \%)$ & $2(1.6 \%)$ & \\
\hline Vessel stenosis/occlusion & $2(0.6 \%)$ & $2(0.6 \%)$ & $0(0 \%)$ & $0(0 \%)$ & $2(1.6 \%)$ & $2(1.6 \%)$ & \\
\hline Persistent complication-related morbidity & $3(1.0 \%)$ & $3(0.9 \%)$ & $2(1.1 \%)$ & $2(0.9 \%)$ & $1(0.8 \%)$ & $1(0.8 \%)$ & \\
\hline Complication-related mortality & $0(0 \%)$ & $0(0 \%)$ & $0(0 \%)$ & $0(0 \%)$ & $0(0 \%)$ & $0(0 \%)$ & \\
\hline Target aneurysm rupture & $2(0.6 \%)$ & $2(0.6 \%)$ & $1(0.5 \%)$ & $1(0.4 \%)$ & $1(0.8 \%)$ & $1(0.8 \%)$ & .19 \\
\hline PcomA (giant) & $1(0.3 \%)$ & $1(0.3 \%)$ & $0(0 \%)$ & $0(0 \%)$ & $1(0.8 \%)$ & $1(0.8 \%)$ & \\
\hline MCA (large) & $1(0.3 \%)$ & $1(0.3 \%)$ & $1(0.5 \%)$ & $1(0.4 \%)$ & $0(0 \%)$ & $0(0 \%)$ & \\
\hline Neurologic mortality & $3(1.0 \%)$ & $3(0.9 \%)$ & $1(0.5 \%)$ & $1(0.4 \%)$ & $2(1.6 \%)$ & $2(1.6 \%)$ & .70 \\
\hline Neurologic morbidity & $7(2.3 \%)$ & $7(2.0 \%)$ & $4(2.1 \%)$ & $4(1.8 \%)$ & $3(2.5 \%)$ & $3(2.3 \%)$ & .85 \\
\hline All-cause mortality & $19(6.1 \%)$ & $19(5.4 \%)$ & $14(7.4 \%)$ & $14(6.3 \%)$ & $5(4.1 \%)$ & $5(3.9 \%)$ & .15 \\
\hline
\end{tabular}

Table 5: Aneurysm-related clinical outcomes

\begin{tabular}{|c|c|c|c|c|}
\hline & $\begin{array}{l}\text { All Patients } \\
(N=310)\end{array}$ & $\begin{array}{l}\text { Patients with } \\
\text { Coiling }(n=188)\end{array}$ & $\begin{array}{l}\text { Patients with Flow } \\
\text { Diverters }(n=122)\end{array}$ & $P$ Value \\
\hline Mortality related to target aneurysm rupture or stroke & $9(2.9 \%)$ & $5(2.7 \%)$ & $4(3.3 \%)$ & .15 \\
\hline Worsening of aneurysm-related symptoms & $10(3.2 \%)$ & $7(3.7 \%)$ & $3(2.5 \%)$ & .79 \\
\hline Long-term good neurologic outcomes (mRS $\leq 2$ ) & $264(85.2 \%)$ & $155(82.4 \%)$ & $109(89.3 \%)$ & .33 \\
\hline
\end{tabular}

Given the high safety profile of endovascular treatment, we have stopped routinely admitting patients to the ICU for monitoring posttreatment and are now sending more patients to a hospital floor after a brief stay in the postoperative recovery unit. These findings are important because they highlight the outcomes of contemporary endovascular treatment options of unruptured aneurysms in a real world setting and in a consecutive series of unselected patients.

\section{Angiographic Outcomes}

The incomplete degree of angiographic aneurysm occlusion and the risk of aneurysm recurrence remain the major limitations of endovascular treatment of cerebral aneurysms. ${ }^{15}$ In our series, we found cumulative complete/near-complete aneurysm occlusion rates of $87.1 \%$. Cumulative complete/nearcomplete occlusion rates were $92.9 \%$ in the coiling group and $77.9 \%$ in the FD group. The high rate of angiographic occlusion at follow-up in aneurysms treated with coil embolization that we observed is in line with other recently published study results. For example, in a series of 4665 treated unruptured aneurysms, Shigematsu et $\mathrm{al}^{16}$ demonstrated a cumulative complete/near-complete aneurysm occlusion rate of $89.6 \%$. Of these, 2690 aneurysms (57.7\%) were completely occluded and
$1490(31.9 \%)$ had small residual necks. The rate of incomplete occlusion following coiling ranged from $1.2 \%$ to $20.8 \%$ in larger studies, ${ }^{17-23}$ similar to our finding of $8 \%$ in the coiling group.

The rate of complete occlusion in the FD group with at least 6 months of follow-up of $64.4 \%$ is lower than that in other flow-diverter studies; however, the low rate of retreatment $(6 \%)$ is in line with those previously reported. ${ }^{24-28}$ In the Pipeline for Uncoilable or Failed Aneurysms Study, ${ }^{24}$ the rate of complete occlusion was $82 \%$ at 6 months and $86 \%$ at 12 months. Likewise, in a large single-center consecutive series of 54 patients, Lylyk et $\mathrm{al}^{25}$ found high rates of complete aneurysm occlusion of $93 \%$ and $96 \%$ at 6 and 12 months, respectively.

In our series, we encountered 3 cases of posttreatment rupture. In comparison, the Cerebral Aneurysm Rerupture After Treatment (CARAT) investigators reported annual rates of rupture after 1 year of $0.11 \%$ (95\% CI, $0 \%-0.63 \%)$ for coiling. However, rerupture rates of incompletely obliterated aneurysms were as high as $17.6 \%$ during a mean follow-up of 4 years, when $<70 \%$ of the aneurysm was occluded. In large series of flow-diversion treatments, ${ }^{2,27-30}$ the incidence of an- 


\begin{tabular}{|c|c|c|c|}
\hline Rupture of Target Aneurysm after Treatment & R MCA & L PcomA Partially Thrombosed & R Carotid Ophthalmic \\
\hline Aneurysm size $(\mathrm{mm})$ & 11 & 38 & 20 \\
\hline Initial treatment & Simple coiling & Partial coiling/PED & PED \\
\hline No. of devices & 6 Coils & 3 Coils/1 PED & 1 PED \\
\hline Initial degree of occlusion & Near-complete & Incomplete & Incomplete \\
\hline \multicolumn{4}{|l|}{ Follow-up imaging } \\
\hline Complete radiologic/angiographic time (mo) & 25.4 & 9.1 & 0.27 \\
\hline First imaging follow-up & DSA & MRA & CTA (emergency) \\
\hline Timing of first imaging follow-up (mo) & 7 & 3 & 8 Days (emergency) \\
\hline Degree of occlusion at first follow-up & Incomplete/recurrence & Incomplete (decrease) & Incomplete \\
\hline Degree of occlusion at last follow-up & Near-complete & Incomplete (decrease) & NA \\
\hline Recurrence/retreatment & $2 \times / 2 \times$ & NA & NA \\
\hline \multicolumn{4}{|l|}{ Retreatment } \\
\hline Size of recurrence $(\mathrm{mm})$ & 5 & & \\
\hline Time (mo) & 7 & & \\
\hline Endovascular technique & Simple coiling & & \\
\hline No. of devices & 2 Coils & & \\
\hline Immediate degree of occlusion & Near-complete & & \\
\hline \multicolumn{4}{|l|}{ Retreatment } \\
\hline Size of recurrence $(\mathrm{mm})$ & 13 & & \\
\hline Time (mo) & 18.5 & & \\
\hline Endovascular technique & Simple coiling & & \\
\hline No. of devices & 7 Coils & & \\
\hline Immediate degree of occlusion & Near-complete & & \\
\hline Rupture time & $2.5 \mathrm{mo}$ & $9.1 \mathrm{mo}$ & 8 days \\
\hline
\end{tabular}

Note:- R indicates right; L, left; PcomA, posterior communicating artery.

eurysm rupture was found to be between $0.4 \%$ and $2.6 \%$. Brinjikji et $\mathrm{al}^{31}$ reported similar results (3\%) in their meta-analysis of published case series.

\section{Clinical Outcomes}

In our series, we observed neurologic morbidity and mortality rates of $2.3 \%$ and $1.0 \%$ for patients, respectively. Only a minority of patients $(3.2 \%)$ reported $\mathrm{mRS}$ worsening related to the target aneurysm or endovascular therapy $(3.7 \%$ in the coiling group and $2.5 \%$ in the FD group). Neurologic morbidity and mortality rates in the FD group were $2.5 \%$ and $1.6 \%$, respectively. This is lower than that reported in the International Retrospective Study of the Pipeline Embolization Device (IntrePED), which reported a combined neurologic morbidity and mortality rate of $8.4 \% .{ }^{29}$ This rate may be due to patient selection because the proportion of patients with treated non-ICA aneurysms in our study was lower than that in IntrePED. Other previously published studies $^{8,26,32-34}$ have reported morbidity and mortality rates following FD treatment ranging from $0 \%$ to $12 \%$ and $0 \%$ to $7 \%$, respectively. $^{31}$

During our study period, we have changed our daily practice of admitting patients with unruptured intracranial aneurysms after treatment directly to the ICU. Arias et $\mathrm{al}^{35}$ showed that most significant postprocedural events (74\%) after uncomplicated aneurysm intervention occur within 4 hours. These events become less frequent with increasing time. Likewise, Eisen et $\mathrm{al}^{36}$ found that in the absence of intraoperative events with the potential for ongoing cerebral ischemia, most patients undergoing elective endovascular treatment of unruptured cerebral aneurysms can be managed without direct ICU admission. Our experience and findings have been similar. ${ }^{37}$ Improved ICU admission rates are likely due to a combination of increasing operator experience and patient selection.

\section{Limitations}

The limitations of this study are related to the absence of randomization and the variable duration of follow-up. However, the data for all patients were collected prospectively. This was a singlecenter case series of aneurysms treated by a group of experienced neurointerventionalists and endovascular neurosurgeons. Thus, our data may not be generalizable to other practices. With increasing experience with the PED, the off-label use of the PED has been widening in our practice, which could contribute to higher complication rates. Another limitation of the study is that there was no independent assessment of angiographic or clinical outcomes. The determination of final radiologic results was by the treating physician. In addition, there were significant differences in the baseline characteristics of patients undergoing coiling and flow-diverter therapy, which could confound our statistical analyses. These limitations notwithstanding, our study summarizes the results in an unselected group of patients with unruptured aneurysms in a real world setting and provides a contemporary view indicating that both endovascular techniques are safe and clinically effective in treating unruptured intracranial aneurysms. No patient was lost to follow-up. Moreover, clinical outcome, in accordance with International Subarachnoid Aneurysm Trial methodology, was by a patient self-assessment. ${ }^{38}$

\section{CONCLUSIONS}

Our study of $>300$ patients with 318 unruptured aneurysms treated with flow-diverter therapy or coil embolization found that endovascular treatment of unruptured aneurysms is both safe and effective. Coil embolization was associated with higher recurrence and retreatment rates, but the rates of poor neurologic outcome were similar between groups. Flow diversion has been a disruptive technology at our institution because $>50 \%$ of unruptured aneu- 
rysms are now treated with this technique. Last, we found that in most cases, routine ICU admission is not necessary, and we have changed our practice accordingly. Our findings highlight the safety and efficacy profile of the endovascular treatment of unruptured aneurysms in a real world setting.

Disclosures: David F. Kallmes—UNRELATED: Board Membership: GE Healthcare (Cost-Effectiveness Board)*; Consultancy: ev3/Covidien/Medtronic, ${ }^{*}$ Comments: planning and implementing clinical trials; Grants/Grants Pending: Sequent Medical,* SurModics, ${ }^{*}$ NeuroSigma, ${ }^{*}$ Codman, ${ }^{*}$ Medtronic, ${ }^{*}$ MicroVention*; Comments: preclinical research and clinical trials; Travel/Accommodations/Meeting Expenses Unrelated to Activities Listed: Medtronic, ${ }^{*}$ Comments: presentation at an FDA panel meeting. Giuseppe Lanzino_UNRELATED: Consultancy: Covidien. * Money paid to the institution.

\section{REFERENCES}

1. Yu SC, Kwok CK, Cheng PW, et al. Intracranial aneurysms: midterm outcome of Pipeline embolization device-a prospective study in $\mathbf{1 4 3}$ patients with 178 aneurysms. Radiology 2012;265:893901 CrossRef Medline

2. Saatci I, Yavuz K, Ozer C, et al. Treatment of intracranial aneurysms using the Pipeline flow-diverter embolization device: a single-center experience with long-term follow-up results. AJNR Am J Neuroradiol 2012;33:1436-46 CrossRef Medline

3. Deutschmann HA, Wehrschuetz M, Augustin M, et al. Long-term follow-up after treatment of intracranial aneurysms with the Pipeline embolization device: results from a single center. AJNR Am J Neuroradiol 2012;33:481-86 CrossRef Medline

4. Maimon S, Gonen L, Nossek E, et al. Treatment of intra-cranial aneurysms with the SILK flow diverter: 2 years' experience with 28 patients at a single center. Acta Neurochir 2012;154:979-87 CrossRef Medline

5. Chiu AH, Cheung AK, Wenderoth JD, et al. Long-term follow-up results following elective treatment of unruptured intracranial aneurysms with the Pipeline embolization device. AJNR Am J Neuroradiol 2015;36:1728-34 CrossRef Medline

6. McAuliffe $\mathrm{W}$, Wycoco $\mathrm{V}$, Rice $\mathrm{H}$, et al. Immediate and midterm results following treatment of unruptured intracranial aneurysms with the Pipeline embolization device. AJNR Am J Neuroradiol 2012; 33:164-70 CrossRef Medline

7. Lanzino G. Editorial: flow diversion for intracranial aneurysms. J Neurosurg 2013;118:405-06; discussion 406-07 CrossRef Medline

8. McDonald RJ, McDonald JS, Kallmes DF, et al. Periprocedural safety of Pipeline therapy for unruptured cerebral aneurysms: analysis of 279 patients in a multihospital database. Interv Neuroradiol 2015;21: 6-10 CrossRef Medline

9. Burrows AM, Cloft H, Kallmes DF, et al. Periprocedural and midterm technical and clinical events after flow diversion for intracranial aneurysms. J Neurointerv Surg 2015;7:646-51 CrossRef Medline

10. Cruz JP, Chow M, O'Kelly C, et al. Delayed ipsilateral parenchymal hemorrhage following flow diversion for the treatment of anterior circulation aneurysms. AJNR Am J Neuroradiol 2012;33:603-08 CrossRef Medline

11. Crobeddu E, Lanzino G, Kallmes DF, et al. Marked decrease in coil and stent utilization following introduction of flow diversion technology. J Neurointerv Surg 2013;5:351-53 CrossRef Medline

12. de Barros Faria M, Castro RN, Lundquist J, et al. The role of the Pipeline embolization device for the treatment of dissecting intracranial aneurysms. AJNR Am J Neuroradiol 2011;32:2192-95 CrossRef Medline

13. Kulcsár Z, Ernemann U, Wetzel SG, et al. High-profile flow diverter (Silk) implantation in the basilar artery: efficacy in the treatment of aneurysms and the role of the perforators. Stroke 2010;41:1690-96 CrossRef Medline

14. Pistocchi S, Blanc R, Bartolini B, et al. Flow diverters at and beyond the level of the circle of Willis for the treatment of intracranial aneurysms. Stroke 2012;43:1032-38 CrossRef Medline
15. Lanzino G, Crobeddu E, Cloft HJ, et al. Efficacy and safety of flow diversion for paraclinoid aneurysms: a matched-pair analysis compared with standard endovascular approaches. AJNR Am J Neuroradiol 2012;33:2158-61 CrossRef Medline

16. Shigematsu T, Fujinaka T, Yoshimine T, et al; JR-NET Investigators. Endovascular therapy for asymptomatic unruptured intracranial aneurysms: JR-NET and JR-NET2 findings. Stroke 2013;44:2735-42 CrossRef Medline

17. Pierot L, Spelle L, Vitry F. Immediate anatomic results after the endovascular treatment of unruptured intracranial aneurysms: analysis of the ATENA series. AJNR Am J Neuroradiol 2010;31:140-44 CrossRef Medline

18. Oishi H, Yamamoto M, Shimizu T, et al. Endovascular therapy of 500 small asymptomatic unruptured intracranial aneurysms. AJNR Am J Neuroradiol 2012;33:958-64 CrossRef Medline

19. Gonzalez N, Murayama Y, Nien YL, et al. Treatment of unruptured aneurysms with GDCs: clinical experience with 247 aneurysms. AJNR Am J Neuroradiol 2004;25:577-83 Medline

20. van Rooij WJ, Sluzewski M. Durability of treatment of intracranial aneurysms with Hydrocoils is not different from standard platinum coils. Stroke 2006;37:2874; author reply 2875 Medline

21. Yue W. Endovascular treatment of unruptured intracranial aneurysms. Interv Neuroradiol 2011;17:420-24 CrossRef Medline

22. Song JH, Chang IB, Ahn JH, et al. Angiographic results of widenecked intracranial aneurysms treated with coil embolization: a single center experience. J Korean Neurosurg Soc 2015;57:250-57 CrossRef Medline

23. Raymond J, Guilbert F, Weill A, et al. Long-term angiographic recurrences after selective endovascular treatment of aneurysms with detachable coils. Stroke 2003;34:1398-403 CrossRef Medline

24. Becske T, Kallmes DF, Saatci I, et al. Pipeline for uncoilable or failed aneurysms: results from a multicenter clinical trial. Radiology 2013; 267:858-68 CrossRef Medline

25. Lylyk P, Miranda C, Ceratto R, et al. Curative endovascular reconstruction of cerebral aneurysms with the Pipeline embolization device: the Buenos Aires experience. Neurosurgery 2009;64:632-42; discussion 642-43; quiz N6 CrossRef Medline

26. Chalouhi N, Zanaty M, Whiting A, et al. Safety and efficacy of the Pipeline embolization device in $\mathbf{1 0 0}$ small intracranial aneurysms. J Neurosurg 2015;122:1498-502 CrossRef Medline

27. Chalouhi N, Starke RM, Yang S, et al. Extending the indications of flow diversion to small, unruptured, saccular aneurysms of the anterior circulation. Stroke 2014;45:54-58 CrossRef Medline

28. Zanaty M, Chalouhi N, Starke RM, et al. Flow diversion versus conventional treatment for carotid cavernous aneurysms. Stroke 2014; 45:2656-61 CrossRef Medline

29. Kallmes DF, Hanel R, Lopes D, et al. International retrospective study of the Pipeline embolization device: a multicenter aneurysm treatment study. AJNR Am J Neuroradiol 2015;36:108-15 CrossRef Medline

30. Briganti F, Napoli M, Tortora F, et al. Italian multicenter experience with flow-diverter devices for intracranial unruptured aneurysm treatment with periprocedural complications-a retrospective data analysis. Neuroradiology 2012;54:1145-52 CrossRef Medline

31. Brinjikji W, Murad MH, Lanzino G, et al. Endovascular treatment of intracranial aneurysms with flow diverters: a meta-analysis. Stroke 2013;44:442-47 CrossRef Medline

32. Berge J, Biondi A, Machi P, et al. Flow-diverter Silk stent for the treatment of intracranial aneurysms: 1-year follow-up in a multicenter study. AJNR Am J Neuroradiol 2012;33:1150-55 CrossRef Medline

33. Leonardi M, Cirillo L, Toni F, et al. Treatment of intracranial aneurysms using flow-diverting Silk stents (BALT): a single centre experience. Interv Neuroradiol 2011;17:306-15 Medline

34. Velioglu M, Kizilkilic O, Selcuk H, et al. Early and midterm results of complex cerebral aneurysms treated with Silk stent. Neuroradiology 2012;54:1355-65 CrossRef Medline

35. Arias EJ, Patel B, Cross DT 3rd, et al. Timing and nature of in-house 
postoperative events following uncomplicated elective endovascular aneurysm treatment. J Neurosurg 2014;121:1063-70 CrossRef Medline

36. Eisen SH, Hindman BJ, Bayman EO, et al. Elective endovascular treatment of unruptured intracranial aneurysms: a management case series of patient outcomes after institutional change to admit patients principally to postanesthesia care unit rather than to intensive care. Anesth Analg 2015;121:188-97 CrossRef Medline

37. Burrows AM, Rabinstein AA, Cloft HJ, et al. Are routine intensive care admissions needed after endovascular treatment of unruptured aneurysms? AJNR Am J Neuroradiol 2013;34:2199-201 CrossRef Medline

38. Molyneux A, Kerr R, Stratton I, et al; International Subarachnoid Aneurysm Trial (ISAT) Collaborative Group. International Subarachnoid Aneurysm Trial (ISAT) of neurosurgical clipping versus endovascular coiling in 2143 patients with ruptured intracranial aneurysms: a randomised trial. Lancet 2002;360:1267-74 CrossRef Medline 